\title{
Association Between Supratotal Glioblastoma Resection and Patient Survival: A Systematic Review and Meta-Analysis
}

\section{Fatih Incekara ${ }^{1,2}$, Stephan Koene ${ }^{2}$, Arnaud J.P.E. Vincent ${ }^{1}$, Martin J. van den Bent ${ }^{3}$, Marion Smits ${ }^{2}$}

\section{Key words \\ - Glioblastoma \\ - Gross total resection \\ - Supratotal resection \\ - Survival}

\section{Abbreviations and Acronyms \\ 5-ALA: 5-Aminolevulinic acid \\ CE: Contrast enhancing \\ CI: Confidence interval \\ FLAIR: Fluid-attenuated inversion recovery \\ GBM: Glioblastoma \\ GRADE: Grades of Recommendation, Assessment, \\ Development, and Evaluation \\ GTR: Gross total resection \\ HR: Hazard ratio \\ IDH: Isocitrate dehydrogenase \\ KPS: Karnofsky performance scale \\ MGMT: Methylguanine-DNA methyltransferase \\ MRI: Magnetic resonance imaging \\ PRISMA: Preferred Reporting Items for Systematic \\ Reviews and Meta-Analyses \\ SPTR: Supratotal resection}

From the Departments of ${ }^{\mathbf{1}}$ Neurosurgery and ${ }^{\mathbf{2}}$ Radiology, and ${ }^{3}$ Brain Cancer Institute, Erasmus Medical Center, University Medical Center Rotterdam, Rotterdam, The Netherlands

To whom correspondence should be addressed:

Fatih Incekara, M.D.

[E-mail: fincekara@erasmusmc.nl]

- Supplementary digital content available online Citation: World Neurosurg. (2019) 127:617-624.

https://doi.org/10.1016/j.wneu.2019.04.092

Journal homepage: www.journals.elsevier.com/worldneurosurgery

Available online: www.sciencedirect.com

1878-8750/\$ - see front matter (c) 2019 Elsevier Inc. All rights reserved.

\section{INTRODUCTION}

Patients with glioblastoma (GBM) have a poor prognosis with a median overall survival of 15 months, despite safe and maximal surgical resection, followed by chemotherapy and/or radiotherapy. ${ }^{\text {I }}$ GBM will typically appear on contrastenhanced magnetic resonance imaging (MRI) studies as a contrast enhancing (CE) tumor with central necrosis. Maximal and safe surgical resection or gross total resection (GTR) of the CE area is currently the main goal of GBM surgery. Both the

BACKGROUND: Gross total resection (GTR) of the contrast enhancing (CE) area will improve the survival of patients with glioblastoma (GBM). However, GBM can infiltrate into the brain parenchyma, beyond the CE margins. It remains unclear whether resection beyond the CE area (supratotal resection [SPTR]) can improve survival without causing additional neurological deficits. The aim of the present meta-analysis was to study the association between SPTR and overall survival of patients of GBM.

METHODS: Embase, PubMed, and other literature databases were searched for eligible studies until August 2018. Studies involving patients with GBM that had compared SPTR with GTR were included in the present study. The main outcome was overall survival, presented as hazard ratios (HRs) with $95 \%$ confidence intervals (Cls) and median overall survival differences with the $95 \% \mathrm{Cls}$.

RESULTS: The meta-analysis, which included 6 studies and 1168 unique patients with GBM, showed that compared with GTR, SPTR of GBM resulted in a $53 \%$ lower risk of mortality at any time during follow-up (HR, 0.47; 95\% Cl, $0.31-$ $0.72 ; P=0.0005)$. The median overall survival of the SPTR group was 6.4 months $(95 \% \mathrm{Cl}, 3.2-9.7)$ longer than the GTR group $(P=0.0001)$. Reports on postoperative deficits were limited, and the quality of evidence was moderate to very low.

CONCLUSIONS: Compared with GTR, SPTR of GBM resulted in a lower risk of mortality and longer median overall survival. However, the quality of evidence of the available studies was poor. Therefore, it remains unclear whether SPTR is safe and actually improves the survival of patients with GBM. Future prospective trials and a standardized definition of SPTR are needed.

survival benefits of GTR and the optimal method to achieve this have been extensively debated in neurosurgical studies.

Brown et al. ${ }^{\mathrm{I}}$ showed, in a systematic review and meta-analysis of 37 studies and 4I,II7 unique patients, that compared with subtotal resection, GTR of the CE area will decrease the risk of mortality, with $28 \%$ at $\mathrm{I}$ year and $\mathrm{I} 6 \%$ at 2 years $(\mathrm{P}<$ o.ooI). Jenkinson et al. $^{2}$ recently showed in a Cochrane review that resection with 5-aminolevulinic acid (5-ALA) fluorescence guidance or intraoperative MRI guidance can increase the extent of GBM resection.

However, GBM is known to infiltrate far beyond the CE margins as seen on MRI into the surrounding edematous $\mathrm{T}_{2}$-weighted fluid-attenuated inversion recovery (FLAIR) hyperintense region. ${ }^{3}$ This raises the question of whether GTR of the CE portion will constitute "total" resection or whether surgical resection should also include a part of the hyperintense $\mathrm{T}_{2}$ weighted FLAIR region to improve survival. It has been suggested that 5-ALA fluorescence accumulates in cancer cells and not only corresponds to the CE portion on MRI but also exceeds this area as vague fluorescence, which corresponds with the portions of GBM often infiltrating into an eloquent brain area. ${ }^{4}$

This concept of so-called supramarginal or supratotal resection (SPTR), is already known in the field of low-grade glioma surgery, ${ }^{5,6}$ because low-grade gliomas 


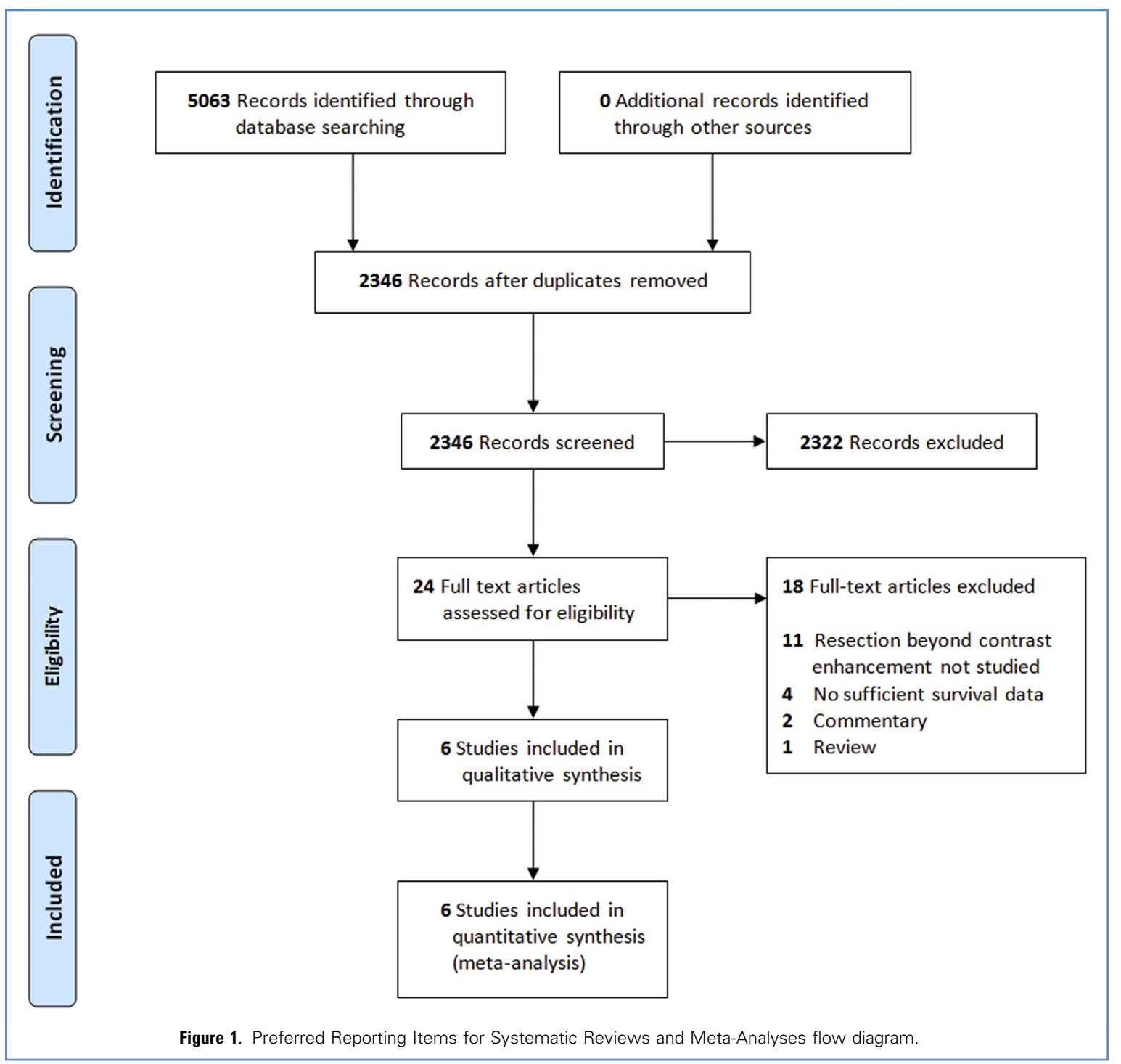

commonly do not enhance and, therefore, lack the CE target for surgical resection. However, SPTR of GBM has been less extensively investigated, and, to the best of our knowledge, no quantitative data analysis has been performed to clarify the association of survival with SPTR versus GTR for patients with GBM and the postoperative neurological complications.

The aim of the present study was to investigate the association between SPTR and survival in patients with GBM using a systematic review and meta-analysis in accordance with the Preferred Reporting Items for Systematic Reviews and MetaAnalyses (PRISMA) guidelines. ${ }^{7}$

\section{METHODS}

Systematic Review

We searched for studies that had included patients with GBM who had undergone surgical resection and had pre- and postoperative MRI studies available. Letters, editorials, abstracts, and non-English citations were excluded. The search query was designed with an expert librarian at the Erasmus University Medical Center, Medical Library, to capture all citations reported until August 2018 within PubMed [(Glioblastoma/ OR (glioblastom* OR (maligna ${ }^{\star} \mathrm{ADJ}_{3}$ glioma ${ }^{\star}$ ) $\mathrm{OR}$ (high ${ }^{\star} \mathrm{ADJ}_{3}$ grade $^{\star} \mathrm{ADJ}_{3}$ glioma $\left.{ }^{\star}\right)$ OR ((grade-iv OR grade-4) $\mathrm{ADJ}_{3}$ glioma $\left.{ }^{\star}\right) \mathrm{OR}$ gbm).ab,ti,kw.) AND (Surgical Procedures, Operative/ OR exp Neurosurgery/ OR Neurosurgical Procedures/ OR exp Brain Neoplasms/su OR (surg^ OR neurosurg ${ }^{\star}$ OR resect ${ }^{\star}$ ).ab,ti,kw.) AND (Margins of Excision/ OR (flair OR (Fluid $\mathrm{ADJ}_{3}$ attenuat ${ }^{\star} \mathrm{ADJ}_{3}$ invers ${ }^{\star} \mathrm{ADJ}_{3}$ recover $\left.{ }^{\star}\right) \mathrm{OR}$ t2 OR t-2 OR gross-total OR ((exten ${ }^{\star}$ OR Supratotal* OR Supramaxim $\left.{ }^{\star}\right) \mathrm{ADJ}_{3}$ (resect* OR remov $\left.{ }^{\star}\right)$ ) OR (( surg $^{\star}$ OR excis $^{\star}$ OR resect $\left.{ }^{\star}\right) \mathrm{ADJ}_{3}$ margin $\left.^{\star}\right) \mathrm{OR}$ ((beyond OR additional ${ }^{\star}$ ) ADJ6 (contrast OR boundar $\left.\left.{ }^{\star}\right)\right)$ ).ab,ti,kw.) NOT (letter ${ }^{\star}$ OR news OR comment* OR editorial ${ }^{\star}$ OR congres $^{\star}$ OR abstract* OR book ${ }^{\star}$ OR 


\begin{tabular}{|c|c|c|c|c|c|c|}
\hline \multirow[b]{2}{*}{ Investigator } & \multirow[b]{2}{*}{ Country } & \multirow[b]{2}{*}{ Definition of GTR } & \multirow[b]{2}{*}{ Definition of SPTR } & \multicolumn{2}{|c|}{ HR } & \multirow[t]{2}{*}{ Quality of Evidence (GRADE) } \\
\hline & & & & $\begin{array}{c}\text { Group } \\
\text { Comparison* }\end{array}$ & $\begin{array}{c}\text { Multivariate } \\
\text { Analysis }\end{array}$ & \\
\hline Aldave et al., ${ }^{12} 2013$ & Spain & $100 \%$ of CE area & $\begin{array}{l}100 \% \text { of CE }+ \text { total resection } \\
\text { of fluorescing tumor }\end{array}$ & Yes & Yes & 3 \\
\hline Li et al., ${ }^{8} 2016$ & USA & $100 \%$ of CE area & $100 \%$ of CE $+>0 \%-100 \%$ FLAIR & Yes & Yes & 2 \\
\hline Eyüpoglu et al.., ${ }^{19} 2016$ & Germany & $100 \%$ of $C E$ area & $\begin{array}{l}100 \% \text { of CE + total resection } \\
\text { of fluorescing tumor }\end{array}$ & Yes & No & 3 \\
\hline Pessina et al., ${ }^{28} 2017$ & Italy & $100 \%$ of $C E$ area & $100 \%$ of CE $+100 \%$ of FLAIR & Yes & Yes & 3 \\
\hline Esquenazi et al., ${ }^{18} 2017$ & USA & $95 \%-100 \%$ of CE area & $>100 \%$ of $\mathrm{CE}$ & Yes & Yes & 3 \\
\hline Glenn et al., 2018 & USA & $100 \%$ of $C E$ area & $\begin{array}{l}100 \% \text { of } C E+>1 \mathrm{~cm} \text { of } \\
\text { surrounding brain tissue }\end{array}$ & Yes & Yes & 4 \\
\hline \multicolumn{7}{|c|}{$\begin{array}{l}\text { GTR, gross total resection; SPTR, supratotal resection; HR, hazard ratio; GRADE, Grades of Recommendation, Assessment, Development, and Evaluation; CE, contrast enhancing; FLAIR, fluid- } \\
\text { attenuated inversion recovery. } \\
\text { * "Yes" indicates the HR should be interpreted as a between group comparison; "no" indicates the HR should be interpreted as per unit of residual T2-weighted FLAIR volume. } \\
\dagger \text { Included prognostic factors in the model such as age, tumor volume, tumor location, Karnofsky performance scale, methylguanine-DNA methyltransferase methylation status, and adjuvant } \\
\text { therapy (Supplemental Table 2). } \\
\ddagger \text { Quality of evidence levels: 1, high; } 2 \text {, moderate; } 3 \text {, low; 4, very low (Supplemental Table 1). }\end{array}$} \\
\hline
\end{tabular}

chapter $^{\star}$ OR dissertation abstract $\left.{ }^{\star}\right)$.pt.] Embase, Web of Science, Cochrane Central, and Google Scholar (search queries for these sources are listed in the Supplemental Materials).

After removing duplicate reports, 2 independent reviewers (F.I. and S.K.) screened the studies by title and abstract and removed off-topic citations. The full text of the remaining reports were independently read by the reviewers (F.I., S.K.) to determine whether they were eligible for final inclusion. Studies of solely pediatric or non-GBM cases, recurrent GBM, nonoperative or surgery of the enhancing tumor portion alone, or biopsy only and studies without survival data were excluded. The present study was performed and presented in accordance with the PRISMA guidelines. ${ }^{7}$

\section{Data Collection}

The main outcome of interest was overall survival, presented as hazard ratios (HRs) with $95 \%$ confidence intervals (CIs), and median overall survival with $95 \%$ CIs of the GTR and SPTR groups. These data were collected from the included studies, calculated from other available data, or extracted based on data points created using a pixelby-pixel method from the survival curves. GTR and SPTR were defined by the authors of the studies included in our meta-analysis. We categorized GTR as $100 \%$ resection of the CE area, and SPTR as every effort to resect beyond GTR of the CE portion, which had been qualitatively or quantitatively defined by the authors of the included studies. Li et al. ${ }^{8}$ presented their data on survival and neurological outcomes mainly by categorizing the resection as $<53 \%$ FLAIR and $\geq 53 \%$ FLAIR. However, after email correspondence with the senior author, we received additional survival data on the GTR and SPTR groups to perform our meta-analysis. ${ }^{8}$ When available, data on postoperative new neurological deficits, surgical complications, and/or quality of life after surgery were collected to assess the safety of both SPTR and GTR.

\section{Meta-Analysis}

The HRs with $95 \%$ CIs and median overall survival with $95 \%$ CIs for the SPTR and GTR groups were collected or calculated for each study using the available data and the random effects model and presented in forest plots using Review Manager (RevMan, version 5.3 [Cochrane Collaboration, London, United Kingdom]). The random effects model was used instead of the fixed effects model because of the heterogeneity among the studies to provide a more conservative and clinically reliable interpretation of the summarized statistics and $95 \%$ CIs. The HRs had been corrected by the authors of the individual studies for several prognostic factors across the studies such as age, Karnofsky performance scale (KPS), adjuvant therapy, tumor volume and location, and methylguanine-DNA methyltransferase (MGMT) methylation and isocitrate dehydrogenase (IDH) mutation status. A P value of $<0.05$ was considered to indicate statistical significance. Heterogeneity was calculated and interpreted using the $\chi^{2}$ test and $\mathrm{I}^{2}$ values with Review Manager (Cochrane Collaboration).

\section{Quality of Evidence}

The quality of evidence obtained from the reports included in the present study was graded using the Grades of Recommendation, Assessment, Development, and Evaluation (GRADE) system ${ }^{9}$ (Supplemental Table 1). Within the GRADE system, 4 levels of quality rating can be assigned to studies: high, often given to randomized controlled trials; moderate or low, often given to observational studies; and very low. The quality of evidence was rated by I of us (F.I.) and was determined from the methodological quality, risk of biases (using the ROBINS-I [risk of bias in nonrandomized studies-of interventions] 
tool), ${ }^{\text {Io }}$ heterogeneity, and precision of effect estimates.

\section{RESULTS}

We identified 1796 citations from Embase, I503 from PubMed, I424 from Web of Science, I40 from Cochrane Central, and 200 from Google Scholar. Removal of the duplicate reports resulted in 2346 unique citations that were screened by title and abstract. A total of 2322 off-topic studies were excluded, leaving 24 that were read in full. ${ }^{6,8, I I-32}$ After reading, I8 reports were excluded owing to the absence of SPTR $(n=I I)$, absence of sufficient survival data $(n=4)$, and article type $(n=3 ; 2$ commentaries and I review). This resulted in a final total of 6 studies $^{8,12,18,19,21,28}$ that were included in our systematic review and meta-analysis. The process of study inclusion is presented in the PRISMA flow diagram in Figure 1, and demographics of the included studies are presented in Table 1.

\section{Meta-Analysis}

Our meta-analysis included 6 studies comparing SPTR and GTR, ${ }^{8,12,18,19,21,28}$ with II68 unique patients with GBM. Our meta-analysis resulted showed that compared with GTR, SPTR of GBM resulted in a $53 \%$ lower risk of mortality at any time during the follow-up period (HR, 0.47 ; 95\% CI, 0.3I-0.72; P = 0.0005; $\mathrm{I}^{2}$, $68 \%$; Figure 2).

The median overall survival for the GTR and SPTR groups was 15.0 months $(95 \% \mathrm{CI}$, 2.9-26.I) and 28.3 months (95\% CI, I2.5-
44.I), respectively ( $\mathrm{P}<\mathrm{0}$.ooor). The survival benefit with SPTR was 13.3 months ( $95 \% \mathrm{CI}$, 3.6-23.I) compared with GTR $(\mathrm{P}=0.007)$. However, the findings from Esquenazi et al., ${ }^{18}$ in particular, influenced the heterogeneity $\left(\mathrm{I}^{2}\right)$ of the median overall survival analysis, possibly owing to the much greater median overall survival for the SPTR group of 54 months within their study. The exclusion of their study in an additional median overall survival analysis showed a decrease of $I^{2}$ from $96 \%$ to $50 \%$. Compared with GTR, SPTR of GBM resulted in a longer median overall survival of 6.4 months (95\% CI, 3.2-9.7; $\mathrm{P}=$ o.oooI; Figure 3).

\section{Quality of Evidence}

No randomized controlled trials were available for inclusion in the present metaanalysis. All the studies were retrospective with a nonrandomized treatment assignment. Using the GRADE guidelines, the studies were assigned to the low-level ${ }^{\mathrm{I} 2, \mathrm{I} 8,19,28}$ quality evidence and then possibly upgraded to a moderate level ${ }^{8}$ or downgraded to a very low level ${ }^{21}$ (Table 1) using previously stated mainly methodological factors such as study design, internal validity, risk of biases, and precision (Supplemental Table 1).

Postoperative New Neurological Deficits In 3 studies, the incidence rates of postoperative new neurological deficits for both SPTR (range, o\%-r $\%$ ) and GTR (range, $\mathrm{O} \%-8 \%$ ) groups were reported. However, in the other 3 studies, these data either were not clearly presented or were absent (Table 2).
Overall, the reports were limited; thus, the difference in postoperative neurological outcomes between SPTR versus GTR could not clearly be analyzed.

\section{DISCUSSION}

The present PRISMA guided systematic review and meta-analysis studied the association between SPTR and survival in patients with GBM. Our analysis included 6 studies and II68 unique patients and showed that compared with GTR, SPTR of GBM resulted in a $53 \%$ lower risk of mortality at any time during the follow-up period and a 6.4-month longer median overall survival duration. The quality of evidence for the available studies, however, was moderate to very low. Furthermore, the incidence rates of postoperative new neurological deficits was minimally and only qualitatively reported. Finally, data on the patients' quality of life were not reported in any of the included studies. It, therefore, remains unclear whether SPTR can be achieved as safely as GTR.

\section{Defining SPTR}

A multitude of definitions have been used for SPTR. The term was first used by Yordanova and Duffau ${ }^{33}$ in 2011 to explain the procedure of low-grade glioma resection guided by functional boundaries, defined by the area of T2-weighted FLAIR hyperintensity during awake surgery, instead of the classic neuronavigation using preoperative MRI contrast-enhanced scans. Yordanova and Duffau ${ }^{33}$ showed

\begin{tabular}{|c|c|c|c|c|c|c|c|c|}
\hline Study & Year & $\begin{array}{l}\text { SPTR } \\
\text { Total }\end{array}$ & $\begin{array}{l}\text { GTR } \\
\text { Total }\end{array}$ & Weight & $\begin{array}{l}\text { Hazard Ratio } \\
\text { IV, Random, } 95 \% \mathrm{CI}\end{array}$ & \multicolumn{3}{|c|}{$\begin{array}{c}\text { Hazard Ratio } \\
\text { IV, Random, } 95 \% \mathrm{CI}\end{array}$} \\
\hline Aldave $^{12}$ & 2013 & 25 & 27 & $11.8 \%$ & $0.39[0.16,0.96]$ & & & \\
\hline Eyupoglu ${ }^{19}$ & 2016 & 30 & 75 & $22.5 \%$ & $0.45[0.29,0.70]$ & & & \\
\hline $\mathrm{Li}^{8}$ & 2016 & 643 & 233 & $28.3 \%$ & $0.77[0.65,0.91]$ & & - & \\
\hline Pessina ${ }^{28}$ & 2017 & 21 & 60 & $15.8 \%$ & $0.60[0.29,1.24]$ & & & - \\
\hline Esquanazi ${ }^{18}$ & 2017 & 25 & 13 & $13.0 \%$ & $0.29[0.12,0.70]$ & & & \\
\hline Glenn $^{21}$ & 2018 & 7 & 9 & $8.6 \%$ & $0.17[0.05,0.57]$ & & & \\
\hline Total $(95 \%$ & & 751 & 417 & $100.0 \%$ & $0.47[0.31,0.72]$ & & & \\
\hline $\begin{array}{l}\text { Heterogene } \\
\text { Test for ove }\end{array}$ & $\begin{array}{l}\text { eity: Tat } \\
\text { erall eff }\end{array}$ & $\begin{array}{l}2=0.16 \\
\mathrm{ct}: Z=\end{array}$ & $\begin{array}{l}; \mathrm{Chi}^{2}= \\
3.51(\mathrm{P}\end{array}$ & $\begin{array}{l}=15.51, \mathrm{df} \\
=0.0005)\end{array}$ & $=5(P=0.008) ; I^{2}=68 \%$ & 0.05 & $\begin{array}{cc}1 & 1 \\
0.2 & 1 \\
\text { favours SPTR }\end{array}$ & $1 \begin{array}{r}1 \\
\text { favours GTR }\end{array}$ \\
\hline
\end{tabular}




\begin{tabular}{|c|c|c|c|c|c|c|c|c|c|c|c|c|}
\hline \multirow[b]{2}{*}{ Study } & \multicolumn{4}{|c|}{ SPTR } & \multicolumn{2}{|c|}{ GTR } & \multirow[b]{2}{*}{ Total } & \multirow[b]{2}{*}{ Weight } & \multirow{2}{*}{$\begin{array}{l}\text { Median Difference } \\
\text { IV, Random, } 95 \% \text { CI [Months] }\end{array}$} & \multirow{2}{*}{\multicolumn{2}{|c|}{$\begin{array}{c}\text { Median Difference } \\
\text { IV, Random, } 95 \% \mathrm{Cl} \text { [Months] }\end{array}$}} & \\
\hline & Year & Median [Months] & SD [Months] & Total & Median [Months] & SD [Months] & & & & & & \\
\hline Aldave ${ }^{12}$ & 2013 & 27 & 11.14 & 25 & 17.5 & 12.64 & 27 & $16.3 \%$ & $9.50[3.03,15.97]$ & & - & \\
\hline $\mathrm{Li}^{8}$ & 2016 & 16.8 & 18.08 & 643 & 13 & 6.97 & 233 & $40.4 \%$ & $3.80[2.14,5.46]$ & & - & \\
\hline Eyupoglu $^{15}$ & ${ }^{9} 2016$ & 18.5 & 11.00 & 30 & 14 & 5.99 & 75 & $26.1 \%$ & $4.50[0.33,8.67]$ & & - & \\
\hline Pessina ${ }^{28}$ & 2017 & 28.6 & 22.62 & 21 & 16.2 & 9.29 & 60 & $8.7 \%$ & $12.40[2.44,22.36]$ & & & \\
\hline Glenn $^{21}$ & 2018 & 24 & 2.81 & 7 & 11 & 15.22 & 9 & $8.4 \%$ & $13.00[2.84,23.16]$ & & & \\
\hline Total $(95 \%$ & $\% \mathrm{Cl}$ & & & 726 & & & 404 & $100.0 \%$ & $6.44[3.17,9.71]$ & & & \\
\hline $\begin{array}{l}\text { Heterogen } \\
\text { Test for ov }\end{array}$ & $\begin{array}{l}\text { veity: Ta } \\
\text { verall ef }\end{array}$ & $\begin{array}{l}u^{2}=6.19 ; \mathrm{Chi}^{2}=8 \\
\text { fect: } Z=3.86(P=\end{array}$ & $\begin{array}{l}08, d f=4(P= \\
0.0001)\end{array}$ & $0.09) ; 1$ & $2^{2}=50 \%$ & & & & & $\begin{array}{c}-10 \\
\text { favours GTR }\end{array}$ & $\begin{array}{c}10 \\
\text { favours SPTR }\end{array}$ & 20 \\
\hline
\end{tabular}

that SPTR of low-grade glioma resulted in a significant delay of anaplastic degeneration $(\mathrm{P}=0.037)$ without causing permanent neurological deficits.

With SPTR of GBM, the classically used CE boundaries of the tumor will be exceeded to include the nonenhancing hyperintense T2-weighted FLAIR region during resection, presumed to represent edematous, tumorinfiltrated tissue. This region can infiltrate deep into eloquent brain areas. $^{3}$ For our analysis, we considered any effort of resection beyond GTR of the CE areas as SPTR, irrespective of the procedure used to achieve the resection. Some studies used a relatively conservative SPTR procedure such as resection of additional residual 5ALA-fluorescent tissue ${ }^{\mathrm{I} 2, \mathrm{I9}}$ or resection of an additional rim $\left(>_{\mathrm{I} \mathrm{cm}}\right)$ after GTR of the CE area. $^{21}$ However, Li et al. ${ }^{8}$ and Pessina et al. $^{28}$ defined SPTR as additional resection of FLAIR abnormalities (range, $>0 \%-100 \%$ ) and $100 \%$ resection of $\mathrm{T}_{2}$ weighted FLAIR hyperintense volumes in addition to GTR of the CE areas, respectively. Additionally, a very recent study defined SPTR as GTR plus frontal or temporal lobectomy, without any volumetric analysis on the T2-weighted FLAIR volumes or functionally defined borders during awake surgery. ${ }^{34}$ Therefore, based on the reported data, SPTR can only broadly be defined as every effort of resection after GTR of the CE portion of GBM. No standardized definition of SPTR exists; thus, SPTR needs to be defined in a prospective setting.

Li et al. ${ }^{8}$ highlighted that compared with GTR the relatively low rates of postoperative new neurological deficits in the SPTR group could probably be explained by the increased use of awake surgery with neurophysiological monitoring, cortical and/or subcortical mapping, and imaging guidance such as intraoperative MRI, functional MRI, and diffusion tensor imaging navigation. ${ }^{2,8}$ Although Jenkinson et al. $^{2}$ showed in a recent Cochrane review that intraoperative MRI or 5-ALA fluorescent-guided surgery can help to increase the extent of GBM resection, the reports on adverse events were incomplete and the studies had very low quality evidence. Because portions of the hyperintense $\mathrm{T}_{2}$ weighted FLAIR area could represent both tumor-infiltrated edematous and solely edematous portions, additional methods to delineate non-CE tumor infiltration are important to obtain a target for SPTR. Resection of the former might contribute to better patient survival, although the impact of the latter on survival will be limited, but could also pose an unnecessary risk of

\section{Table 2. Reported Incidence Rates of Postoperative Neurological Deficits}

\begin{tabular}{|c|c|c|c|c|}
\hline Investigator & GTR & SPTR & $P$ Value & Comment \\
\hline Aldave et al., ${ }^{12} 2013$ & $2(8)$ & $4(18.5)$ & 0.27 & No details on deficits reported \\
\hline Li et al.. ${ }^{8} 2016$ & NA & $120(19)$ & NA & $\begin{array}{l}\text { Motor deficits and speech and visual impairments were the } \\
\text { most commonly reported } 30 \text {-day postoperative neurological } \\
\text { complications }\end{array}$ \\
\hline Glenn et al. ${ }^{21} 2018$ & $0(0)$ & $1(11.1)$ & 0,66 & One patient with dysphasia \\
\hline Pessina et al., ${ }^{28} 2017$ & $0(0)$ & $0(0)$ & NA & $\begin{array}{l}\text { No patient developed postoperative new neurological } \\
\text { deficits in either group }\end{array}$ \\
\hline Eyüpoglu et al., ${ }^{19} 2016$ & NA & NA & $0.47-1.0$ & $\begin{array}{l}\text { Rates on postoperative new neurological deficits between } \\
\text { groups not clearly collectable; overall, no significant } \\
\text { worsening of motor, visual, speech, or cognitive deficits or } \\
\text { seizures reported in either group }\end{array}$ \\
\hline Esquenazi et al., ${ }^{18} 2017$ & NA & NA & NA & $\begin{array}{c}\text { Of } 38 \text { patients, } 3(7.9 \%) \text { had transient and } 2(5.3 \%) \text { had } \\
\text { permanent neurological deficits; group-specific data not } \\
\text { reported }\end{array}$ \\
\hline
\end{tabular}


complications. In addition to 5-ALA, physiological preoperative MRI such as positron emission tomography MRI might help to identify tumor-infiltrated, highly metabolic portions outside the CE areas of GBM as a specific target during surgery. ${ }^{35}$

\section{Study Limitations}

Overall, the results of our analysis should be interpreted with caution because of several limitations. First, the betweenstudy heterogeneity $\left(\mathrm{I}^{2}=68 \%\right)$ across the analyzed studies, which possibly arose from several factors, included the differences in defining SPTR, the heterogeneous or limited sizes of the small study populations across the studies, and their retrospective design and nonrandomized treatment assignment. As stated previously, the different definitions of SPTR across the studies, which were often retrospectively defined and varied between additional resection of fluorescing tumor tissue to total resection of $\mathrm{T} 2$-weighted FLAIR hyperintensity in addition to GTR of the CE area, made it challenging to draw clear conclusions that would benefit the clinical practice of neurosurgeons. Second, because the survival benefit and safety of resecting T2-weighted FLAIR hyperintense regions remains unclear, no clinical equipoise was found to randomize patients with GBM into SPTR or GTR groups. Therefore, SPTR was probably performed for only a selected group of patients, because extending the limits of GBM resection beyond the $\mathrm{CE}$ area was often not the main goal of the surgery, especially not for tumors located in eloquent brain areas.

Finally, a heterogeneous patient population with different prognostic factors such as age, KPS score, adjuvant therapy, IDH mutation and MGMT methylation status, and tumor volume and location were present across the 6 studies (Supplemental Table 2). Although corrections for some of these factors were applied in the multivariate analyses across the studies, the real effect of these factors for achieving SPTR and survival were difficult to determine owing to the retrospective nature of the studies. GBM location and the nearness of the tumor to eloquent areas is a known important prognostic factor. A very recent study suggested that GBMs located in noneloquent areas such as the frontal or temporal pole could possibly undergo safe
SPTR with total lobectomy. ${ }^{34}$ However, no clear comparison with GBMs located in eloquent areas was available. In the reports we included in our study, only limited correction for GBM eloquence was performed (Supplemental Table 2). Furthermore, some of these factors, such as genetic mutations and location and tumor size, are intercorrelated; thus, their influence on survival would be difficult to investigate retrospectively. Patients with GBM with an IDH mutation (and MGMT methylation) will have significantly better survival, although, at the same time, these tumors have more often been located in the frontal pole and have had a larger size..$^{36}$

These limitations introduced biases such as confounding by indication, available information, and selection biases in the analyzed studies, which, consequently, negatively influenced the internal validity and quality of the studies. Because the quality of evidence of the analyzed studies were only moderate to very low, the benefit of SPTR of GBM on survival and its safety remains unclear and, thus, should not yet be considered as a main goal of GBM surgery.

With consideration of these limitations, we used a random effects model to provide a conservative, but clinically more reliable and meaningful, interpretation of the treatment effect of SPTR. ${ }^{37}$ The random effects model summary results of a HR of $0.47(95 \% \mathrm{CI}, 0.3 \mathrm{I}-0.72)$ and median overall survival benefit of 6.4 months ( $95 \%$ CI, 3.2\%-9.7\%) provides a more reliable average estimate effect because it considers the real differences in the SPTR versus GTR effect in each study and provides greater uncertainty around the estimate compared with the fixed effects model summary results of a HR of $0.67(95 \% \mathrm{CI}, 0.58-0.78)$ and a median overall survival benefit of 4.6 months (95\% CI, 3.9-6.o).

In addition, SPTR should not be attempted at any cost. As always, the aim of GBM surgery should be to maximize the extent of GBM resection without causing new neurological deficits and maintaining a good quality of life for patients. Any potential benefits of prolonged survival by extending the tumor resection could be considered by exploring the functional boundaries during awake surgery and additional imaging adjuncts such intraoperative MRI, ultrasound, and 5-ALA guidance. This potential benefit should be weighed, together with the patient, against the risk of extending the boundaries of GBM resection and its effect on postoperative neurological functioning and quality of life.

In our study, the incidence of postoperative new neurological deficits was not well reported across the different studies. Postoperative neurological status was reported only descriptively, without the use of validated tests and quantitative outcome measures. Additionally, no data on patient quality of life were reported across the studies. The safety of the procedure, therefore, could not be established.

\section{Future Directions}

Future, well-designed, prospective, randomized controlled trials are needed to investigate both the safety and the survival benefit of SPTR of GBM. These trials should include prospective and clearly defined volumetric SPTR measures to standardize the definition of SPTR. Such a standardized definition of SPTR would be expected to improve comparability between studies and improve the quality of evidence of studies investigating SPTR of GBM. Advanced physiological imaging techniques could also be used to identify non-CE-infiltrating, residual tumor beyond the CE margins. Finally, validated measures for postoperative neurological outcomes and quality of life assessments (i.e., European Organization for Research and Treatment of Cancer core quality of life questionnaire and/or brain cancer module) that have been corrected for important prognostic factors such as age, KPS score, use of adjuvant therapy, and IDH mutation and MGMT methylation status should be used to study the benefit of SPTR of GBM on patient survival and safety. ${ }^{38}$

\section{CONCLUSIONS}

To the best of our knowledge, we have performed the first meta-analysis of SPTR for GBM. Our results suggest that compared with GTR, SPTR of GBM results in a lower risk of mortality at any time during the follow-up period and longer overall median survival. These results should, however, be interpreted with caution, because the quality of the available evidence was only moderate to very 
low. In addition, no consensus has been reached on the definition of SPTR, and no reliable information on the safety of SPTR was available. Therefore, from the current available data, the benefit of SPTR of GBM on survival and its safety remains unclear and should not yet be considered as the standard of care for GBM surgery. Our findings, however, should encourage further investigation in well-designed, prospective, randomized trials to clarify whether SPTR can be achieved safely to improve the survival of patients with GBM.

\section{ACKNOWLEDGMENTS}

We would like to thank Wichor Bramer, biomedical information specialist from the Erasmus Medical Center University Medical Library, for his assistance with designing the search query. We also would like to thank Professor Raymond Sawaya for providing us with additional information on their study after e-mail correspondence.

\section{REFERENCES}

I. Brown TJ, Brennan MC, Li M, et al. Association of the extent of resection with survival in glioblastoma: a systematic review and meta-analysis. JAMA Oncol. 2016;2:1460-1469.

2. Jenkinson MD, Barone DG, Bryant A, et al. Intraoperative imaging technology to maximise extent of resection for glioma review. Cochrane Database Syst Rev. 20I8;I:CDoI2788.

3. Eidel O, Burth S, Neumann JO, et al. Tumor infiltration in enhancing and non-enhancing parts of glioblastoma: a correlation with histopathology. PLoS One. 20I7;12:eor69292.

4. Díez Valle R, Tejada Solis S, Idoate Gastearena MA, García De Eulate R, Domínguez Echávarri P, Aristu Mendiroz J. Surgery guided by 5 -aminolevulinic fluorescence in glioblastoma: volumetric analysis of extent of resection in single-center experience. J Neurooncol. 20II;IO2: IO5-II3.

5. Duffau H. A new philosophy in surgery for diffuse low-grade glioma (DLGG): oncological and functional outcomes. Neurochirurgie. 2013;59:2-8.

6. Duffau H. Is supratotal resection of glioblastoma in noneloquent areas possible? World Neurosurg. 20I4;82:EIOI-EIO3.

7. Moher D, Liberati A, Tetzlaff J, Altman DG, Group P. Preferred reporting items for systematic reviews and meta-analyses: the PRISMA statement. BMJ. 2009;339:b2535.

8. Li YM, Suki D, Hess K, Sawaya R. The influence of maximum safe resection of glioblastoma on survival in 1229 patients: can we do better than gross-total resection? J Neurosurg. 20I6;124: 977-988.
9. Guyatt GH, Oxman AD, Vist GE, et al. GRADE: an emerging consensus on rating quality of evidence and strength of recommendations. BMJ. 2008;336: 924-926.

Io. Sterne JA, Hernan MA, Reeves BC, et al. ROBINSI: a tool for assessing risk of bias in nonrandomised studies of interventions. BMJ. 20I6; 355:149I9.

II. Abd-El-Barr MM, Chiocca EA. How much is enough? The question of extent of resection in glioblastoma multiforme. World Neurosurg. 2014;82: eIog-eiro.

I2. Aldave G, Tejada S, Pay E, et al. Prognostic value of residual fluorescent tissue in glioblastoma patients after gross total resection in 5aminolevulinic acid-guided surgery. Neurosurgery. 2013;72:915-920.

13. Bahrami N, Piccioni D, Karunamuni R, et al. Edge contrast of the FLAIR hyperintense region predicts survival in patients with high-grade gliomas following treatment with bevacizumab. AJNR Am J Neuroradiol. 2018;39:I0I7-I024.

I4. Catapano G, Sgulò FG, Seneca V, Lepore G, Columbano L, di Nuzzo G. Fluorescein-guided surgery for high-grade glioma resection: an intraoperative "contrast-enhancer". World Neurosurg. 2017;104:2-5.

I5. Coburger J, Engelke J, Scheuerle A, et al. Tumor detection with 5-aminolevulinic acid fluorescence and Gd-DTPA-enhanced intraoperative MRI at the border of contrast-enhancing lesions: a prospective study based on histopathological assessment. Neurosurg Focus. 2014;36:E3.

I6. Coburger J, Hagel V, Wirtz CR, König R. Surgery for glioblastoma: impact of the combined use of 5aminolevulinic acid and intraoperative MRI on extent of resection and survival. PLoS One. 2015;I0: eoI3I 872 .

I7. Elson A, Bovi J, Siker M, Schultz C, Paulson E. Evaluation of absolute and normalized apparent diffusion coefficient (ADC) values within the postoperative T2/FLAIR volume as adverse prognostic indicators in glioblastoma. J Neurooncol. 2015;122: 549-558.

I8. Esquenazi Y, Friedman E, Liu Z, Zhu JJ, Hsu S, Tandon N. The survival advantage of "supratotal" resection of glioblastoma using selective cortical mapping and the subpial technique. Neurosurgery. 20I7;8I:275-288.

I9. Eyüpoglu IY, Hore N, Merkel A, Buslei R, Buchfelder M, Savaskan N. Supra-complete surgery via dual intraoperative visualization approach (DiVA) prolongs patient survival in glioblastoma. Oncotarget. 2016;7:25755-25768.

20. Gessler F, Forster MT, Duetzmann S, et al. Combination of intraoperative magnetic resonance imaging and intraoperative fluorescence to enhance the resection of contrast enhancing gliomas. Neurosurgery. 2015;77:16-22.

2I. Glenn CA, Baker CM, Conner AK, et al. An examination of the role of supramaximal resection of temporal lobe glioblastoma multiforme. World Neurosurg. 20I8;II4:e747-e755.
22. Grabowski MM, Recinos PF, Nowacki AS, et al Residual tumor volume versus extent of resection: predictors of survival after surgery for glioblastoma. J Neurosurg. 20I4;I2I:III5-II23.

23. Grossman R, Shimony N, Shir D, et al. Dynamics of FLAIR volume changes in glioblastoma and prediction of survival. Ann Surg Oncol. 2017;24: 794-80o.

24. Mampre D, Ehresman J, Pinilla-Monsalve G, et al. Extending the resection beyond the contrastenhancement for glioblastoma: feasibility, efficacy, and outcomes. $\mathrm{Br} \mathrm{J}$ Neurosurg. 2018;32 $528-535$.

25. Marko NF, Weil RJ, Schroeder JL, Lang FF, Suki D, Sawaya RE. Extent of resection of glioblastoma revisited: personalized survival modeling facilitates more accurate survival prediction and supports a maximum-safe-resection approach to surgery. J Clin Oncol. 2014;32:774-782.

26. Meyer RB, Bates LM, Goerss SJ, et al. Awake craniotomy for aggressive resection of primary gliomas located in eloquent brain. Mayo Clin Proc 200I; $76: 677-687$.

27. Neira JA, Ung TH, Sims JS, et al. Aggressive resection at the infiltrative margins of glioblastoma facilitated by intraoperative fluorescein guidance. J Neurosurg. 2017;I27:III-I22.

28. Pessina F, Navarria P, Cozzi L, et al. Maximize surgical resection beyond contrast-enhancing boundaries in newly diagnosed glioblastoma multiforme: is it useful and safe? A single institution retrospective experience. J Neurooncol. 2017; I35:I29-I39.

29. Quan GM, Zheng YL, Yuan T, Lei JM. Increasing FLAIR signal intensity in the postoperative cavity predicts progression in gross-total resected highgrade gliomas. J Neurooncol. 2018;137:63I-638.

30. Schucht P, Knittel S, Slotboom J, et al. 5-ALA complete resections go beyond MR contrast enhancement: shift corrected volumetric analysis of the extent of resection in surgery for glioblas toma. Acta Neurochir. 2014;156:305-312.

31. Yan JL, Van Der Hoorn A, Larkin T), Boonzaier NR, Matys T, Price SJ. Extent of resection of peritumoral diffusion tensor imaging detected abnormality as a predictor of survival in adult glioblastoma patients. J Neurosurg. 2017;126: 234-24I.

32. Yordanova YN, Duffau H. Supratotal resection of diffuse gliomas - an overview of its multifaceted implications. Neurochirurgie. 2017;63:243-249.

33. Yordanova YN, Moritz-Gasser S, Duffau H. Awake surgery for WHO grade II gliomas within "noneloquent" areas in the left dominant hemisphere: toward a "supratotal" resection: clinical article. J Neurosurg. 20II;II5:232-239.

34. Roh TH, Kang SG, Moon JH, et al. Survival benefit of lobectomy over gross-total resection without lobectomy in cases of glioblastoma in the noneloquent area: a retrospective study [e-pub ahead of print]. J Neurosurg https://doi.org/I0.3I7I/20I8. I2.JNSI82558, accessed March I, 2019. 
35. John F, Bosnyak E, Robinette NL, et al. Multimodal imaging-defined subregions in newlydiagnosed glioblastoma: impact on overall survival [e-pub ahead of print]. Neuro Oncol https:// doi.org/Io.I093/neuroonc/noyr69. accessed October 22, 2018.

36. Smits M, van den Bent MJ. Imaging correlates of adult glioma genotypes. Radiology. 2017;284: 3I6-33I.

37. Riley RD, Higgins JP, Deeks JJ. Interpretation of random effects meta-analyses. BMJ. 20II;342: d549.
38. Gessler F, Bernstock JD, Braczynski A, et al. Surgery for glioblastoma in light of molecular markers: impact of resection and MGMT pro moter methylation in newly diagnosed IDH-1 wild-type glioblastomas. Neurosurgery. 2019;84: I90-I97.

Conflict of interest statement: The authors declare that the article content was composed in the absence of any commercial or financial relationships that could be construed as a potential conflict of interest.

Received 8 February 2019; accepted 10 April 2019
Citation: World Neurosurg. (2019) 127:617-624

https://doi.org/10.1016/j.wneu.2019.04.092

Journal homepage: www.journals.elsevier.com/worldneurosurgery

Available online: www.sciencedirect.com

1878-8750/\$ - see front matter (C) 2019 Elsevier Inc. All rights reserved. 


\section{SUPPLEMENTAL MATERIALS}

\section{Search Queries for Several Literature} Sources

Embase.com. ('glioblastoma'/exp OR (glioblastom^ ${ }^{\star}$ OR (maligna ${ }^{\star}$ NEAR/3 glioma ${ }^{\star}$ ) OR (high ${ }^{\star}$ NEAR/3 grade ${ }^{\star}$ NEAR/3 glioma ${ }^{\star}$ ) OR ((grade-iv OR grade-4) NEAR/3 glioma ${ }^{\star}$ ) OR gbm):ab,ti,kw) AND ('surgery'/de OR 'neurosurgery'/exp OR 'cancer surgery'/exp OR 'brain surgery'/exp OR 'brain tumor'/ exp/dm_su OR 'surgical technique'/de OR ( surg $^{\star}$ OR neurosurg ${ }^{\star} \mathrm{OR}$ resect ${ }^{\star}$ ):ab,ti,kw) AND ('extent of resection'/de OR 'surgical margin'/exp OR 'fluid attenuated inversion recovery'/de OR 'fluid attenuated inversion recovery imaging'/de OR 'gross total resection'/de OR (flair OR (Fluid NEAR/3 attenuat ${ }^{\star} \mathrm{NEAR} / 3$ invers ${ }^{\star} \mathrm{NEAR} / 3$ recover ${ }^{\star}$ ) OR t2 OR t-2 OR gross-total OR ( (exten ${ }^{\star}$ OR
Supratotal $^{\star}$ OR Supramaxim $\left.{ }^{\star}\right)$ NEAR/3 (resect* OR remov $\left.{ }^{\star}\right)$ ) OR ((surg ${ }^{\star}$ OR excis ${ }^{\star}$ OR resect $\left.{ }^{\star}\right) \mathrm{NEAR} / 3$ margin $^{\star}$ ) OR ((beyond OR additional ${ }^{\star}$ ) NEAR/6 (contrast OR boundar $\left.\left.{ }^{\star}\right)\right)$ ):ab,ti,kw) NOT ([Conference Abstract]/lim OR [Letter]/lim OR [Note]/ $\lim$ OR [Editorial]/lim)

Web of Science. ((glioblastom^ ${ }^{\star}$ OR (maligna $^{\star}$ NEAR/3 glioma ${ }^{\star}$ ) OR (high ${ }^{\star} \mathrm{NEAR} / 3$ grade $^{\star}$ NEAR/3 glioma ${ }^{\star}$ ) OR ((grade-iv OR grade-4) NEAR/3 glioma ${ }^{\star}$ ) OR gbm):ab,-

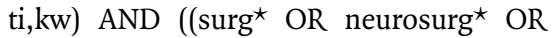
resect $\left.\left.^{\star}\right): a b, t i, k w\right)$ AND ((flair OR (Fluid NEAR $/ 3$ attenuat ${ }^{\star} \mathrm{NEAR} / 3$ invers ${ }^{\star} \mathrm{NEAR} / 3$ recover $\left.{ }^{\star}\right)$ OR t2 OR t-2 OR gross-total OR ((exten ${ }^{\star}$ OR Supratotal ${ }^{\star}$ OR Supramaxim $\left.{ }^{\star}\right)$ NEAR/3 (resect $^{\star}$ OR remov $\left.{ }^{\star}\right)$ ) OR ((surg ${ }^{\star}$ OR excis ${ }^{\star}$ OR resect $\left.{ }^{\star}\right)$ NEAR/3 margin ${ }^{\star}$ ) OR ((beyond OR additional ${ }^{\star}$ ) NEAR/6 (contrast OR boundar $\left.{ }^{\star}\right)$ )):ab,ti,kw)
Cochrane CENTRAL. ((glioblastom ${ }^{\star}$ OR (maligna ${ }^{\star}$ NEAR/3 glioma ${ }^{\star}$ ) OR (high ${ }^{\star}$ $\mathrm{NEAR} / 3$ grade NEAR/3 glioma $^{\star}$ ) OR ((grade-iv OR grade-4) NEAR/3 glioma ${ }^{\star}$ ) OR gbm):ab,ti,kw) AND ((surg* OR neurosurg $^{\star}$ OR resect $\left.\left.{ }^{\star}\right): a b, t i, k w\right)$ AND ((flair OR (Fluid NEAR/3 attenuat* NEAR/3 invers ${ }^{\star} \mathrm{NEAR} / 3$ recover $\left.{ }^{\star}\right)$ OR t2 OR "t $2 "$ OR "gross total" OR ((exten* OR Supratotal $^{\star}$ OR Supramaxim ${ }^{\star}$ ) NEAR/3 (resect* $^{\star}$ OR remov $\left.{ }^{\star}\right)$ ) OR ((surg* OR excis* OR resect $\left.^{\star}\right) \mathrm{NEAR} / 3$ margin $\left.{ }^{\star}\right)$ OR ((beyond OR additional ${ }^{\star}$ ) NEAR/6 (contrast OR boundar $\left.{ }^{\star}\right)$ )):ab,ti,kw)

Google Scholar. glioblastoma|"malignant glioma"|"high grade glioma" flair|"Fluid attenuating inverse"|"gross total"|"Supratotal|Supramaximal resection"|"extent of resection"

Supplemental Table 1. Grades of Recommendation, Assessment, Development, and Evaluation Quality Ranking

\begin{tabular}{|c|c|c|c|c|}
\hline Investigator & Quality Level* & Underlying Study Method & Risk of Bias $\dagger$ & Precision \\
\hline Aldave et al., ${ }^{12} 2013$ & 3 & Nonrandom treatment allocation, retrospective & Moderate & Low patient numbers; wide $95 \% \mathrm{Cls}$ \\
\hline Li et al., 2016 & 2 & Nonrandom treatment allocation retrospective & Moderate & High patient numbers, narrow $95 \% \mathrm{Cls}$ \\
\hline Eyüpoglu et al., ${ }^{19} 2016$ & 3 & Nonrandom treatment allocation retrospective & Moderate & Moderate patient numbers and $95 \% \mathrm{Cls}$ \\
\hline Pessina et al., ${ }^{28} 2017$ & 3 & Nonrandom treatment allocation retrospective & Moderate & Moderate patient numbers and $95 \% \mathrm{Cls}$ \\
\hline Esquenazi et al., ${ }^{18} 2017$ & 3 & Nonrandom treatment allocation retrospective & Moderate & Low patient numbers, wide $95 \% \mathrm{Cls}$ \\
\hline Glenn et al., ${ }^{21} 2018$ & 4 & Nonrandom treatment allocation, retrospective & Serious & Low patient numbers, wide $95 \% \mathrm{Cls}$ \\
\hline \multicolumn{5}{|c|}{$\begin{array}{l}\mathrm{Cl} \text {, confidence interval. } \\
\text { *Quality of evidence levels (Grades of Recommendation, Assessment, Development, and Evaluation Quality): 1, high; } 2 \text {, moderate; 3, low; 4, very low. } \\
\dagger \text { †ROBINS-I (risk of bias in nonrandomized studies - of interventions) tool, based on risks of selection, information, and confounding biases, with summarized judgments that include moderate, } \\
\quad \text { serious, and critical risks of bias or no information. }\end{array}$} \\
\hline
\end{tabular}


Supplemental Table 2. Overview of Multivariate Analyses Across Studies with Adjustment for Prognostics Factors

\section{Investigator}

Aldave et al., ${ }^{12} 2013$

Li et al., ${ }^{8} 2016$

Eyüpoglu et al., ${ }^{19} 2016$

Pessina et al., ${ }^{28} 2017$

Esquenazi et al., ${ }^{18} 2017$

Glenn et al., ${ }^{21} 2018$
Multivariate Analysis

\section{Prognostic Factors as Variables}

Yes

Age, KPS score, MGMT methylation status, tumor eloquent location, preoperative tumor volume, adjuvant therapy

Unclear, at least treatment history

Yes

Not performed

No

Age, extent of CE resection, tumor location

Yes

Age, tumor volume, KPS score, intraoperative mapping, BCNU wafer

Yes

MGMT methylation status, tumor laterality

KPS, Karnofsky performance scale; MGMT, methylguanine-DNA methyltransferase; CE, contrast enhancing; BCNU, bis-chloroethylnitrosourea (or carmustine) 